\title{
Inspection of rivets and cracks in metal using thermography methods
}

\author{
by G. Riegert, Th. Zweschper, A. Dillenz, G. Busse
}

University of Stuttgart, Institute of Polymer Testing and Polymer Science (IKP),

Department of Nondestructive Testing, Pfaffenwaldring 32, 70569 Stuttgart, Germany

\begin{abstract}
Though modern non-metals attract a lot of interest there are still many applications where metallic structures are being used and where safety depends on the integrity of structures, especially if they suffer from aging. Two topics of relevance for aging aircraft are fatigue cracks and rivets. The reliability of inspection relates also to the safe operation of vehicles and trains. We will discuss the application of thermography with optical or ultrasonic excitation to detect such defects.
\end{abstract}

\section{Introduction}

Lockin Thermography uses thermal waves [1] for imaging. With photo-thermal techniques the phase angle of the detected thermal wave with respect to the initial excitation wave is used for imaging of thermal features like cracks, delaminations, and other kinds of thermal boundaries [2-5]. By variation of the lockin frequency (which is the frequency of modulated excitation) the depth range can be adjusted thereby allowing for depth resolved measurement of subsurface features [6].

The different methods of Lockin Thermography are based on different excitation sources. Optical Lockin Thermography (OLT) uses halogen lamps, flash lamps or lasers [7,8], energy deposition is also possible with eddy current or hot air [12]. Ultrasound Lockin Thermography (ULT) uses the losses of elastic wave energy for heating [9-12].

Both OLT and ULT are suited for characterization of rivets and cracks $[13,14]$. In this paper we present results obtained on rivets with Ultrasound Burst Phase Thermography (UBP) [15-17], which is a further development of the defect selective Ultrasound Lockin Thermography technique. It uses a short rectangular ultrasound burst, which includes a frequency spectrum for lock-in examination. The advantages of this method are a shorter measurement duration, a reduced thermal load on the sample, and the possibility of analyzing at different frequencies (and hence with different depth ranges).

Loose rivets or cracks are areas of enhanced losses. After injection of ultrasonic elastic waves they heat up selectively due to hysteresis. This is why ULT and UBP are defect selective methods. The generated thermal wave propagates to the surface of the sample where it is detected by the infrared camera. The Fourier transformation provides amplitude and phase image of the local thermal wave signals at the specific frequency components of modulation. The advantage of these dark field methods is the enhanced probability of defect detection (POD), also with less well-trained maintenance staff. Confusing features of intact thermal structures, which are seen in OLT, are suppressed in ULT/UBP.

\section{Experimental Set-up}

The experimental set-up (figure 1) is used for excitation with both elastic and optical waves. UBP as one kind of "elastic wave thermography" uses for excitation a sonotrode, which has to be clamped on the surface of the sample. The sonotrode, which actually is designed for polymer welding, consists of a piezo stack with a maximum ultrasound power of $2 \mathrm{~kW}$ at a frequency of $20 \mathrm{kHz}$. However, the ultrasound power actually injected into the sample is usually around several hundred Watts due e.g. to impedance mismatch of the 
sonotrode/sample material. The big advantage of UBP is the short image acquisition time of about 10 seconds.

For Optical Lockin Thermography (OLT) or Optical Burst Phase Thermography (OBP) we use halogen or flash lamps, respectively, for sample excitation (figure 1). For measurements on aluminum laser beam welding (see figure 5) a thermal wave transmission mode configuration is chosen where the flash lamp is located on one side of the sample and the infrared camera on the other side. After the flash, the camera records several hundred frames at a frame rate of $100 \mathrm{~Hz}$. A Fourier transformation then reveals an amplitude and a phase image like in UBP.

\section{Results}

\subsection{Rivets in different sheet material joints}

The investigation on two model samples was performed using UBP with 200 ms burst duration and $1.6 \mathrm{~kW}$ nominal power (figure 2). One sample is a joint of two aluminum sheets with six rivets; the other sample is a riveted joint of an aluminum sheet (bottom) on a CFRP sheet (top). Both samples have damaged rivets.

Image acquisition was five seconds with a frame rate of $100 \mathrm{~Hz}$. The amplitude images (Figure 2, top) evaluated at $0.21 \mathrm{~Hz}$ show basically the thermal structure of the samples. At the Al-Al joint (left) the damaged rivet cannot be revealed, while it already can be seen in the CFRP-Al joint (right). This could be because of the relatively low heat conductivity of CFRP, while the heat flows off rapidly at the aluminum joint.

In the phase images of $0.21 \mathrm{~Hz}$ (Figure 2, bottom) the damaged rivets can be seen clearly in both joints, which shows that the phase responds more sensitively to defects.

\subsection{Punched rivets}

In a punched rivet joint of two steel sheets (figure 3 ) the left rivet has a good undercut while the right rivet was incorrectly applied (see upper cross section images). The lower left phase image (evaluated at $0.54 \mathrm{~Hz}$ ) of the good rivet shows only noise as no heat is produced in it. The phase image of the poor quality rivet (figure 3, lower right) shows clearly the areas with enhanced mechanical losses underneath the rivet. The poor riveting of the sheets allows for their relative motion that produces heat at ultrasonic excitation. This can be seen in the phase angle change around the rivet.

\subsection{Wing-Box of Do 31}

The experimental Do 31 was a jet cargo plane built in 1967 for vertical takeoff and landing. The investigated sample is a part of a wing-box of this plane after torque testing.

In the left lower corner of the photograph showing the wing-box (figure 4, left) the sonotrode for ultrasonic excitation can be seen. The test was performed with the Ultrasound Burst Phase method (burst length $500 \mathrm{~ms}$ with $2 \mathrm{~kW}$ ). In the amplitude image at a frequency of $0.175 \mathrm{~Hz}$ (middle of figure 4) no damages are visible (the black spots are the strain gauges from the previous torque test). The structure which is visible on the surface of the sample is the reflection of the noise-insulated room in which the UBP testing is done, as the blank aluminium sheets are very good mirrors at the infrared wavelength $(3$ to $5 \mu \mathrm{m})$ and the wing-box was moving slightly during the measurement (due to the excitation).

In the phase image (figure 4, right) reflections and thermal structure of the wing box are suppressed, only areas with enhanced loss angle are imaged. There are several loose rivets visible as bright spots. As the elastic wave amplitudes are damped with increasing propagation they become too low to produce heat in remote areas of the injection point (for example in the upper right corner of the wing-box). 


\subsection{Laser beam welding}

For the inspection of a laser beam welding (figure 5) with OBP in the transmission mode [18] a flash lamp is used to illuminate the rear side of the sample while the IRCamera is monitoring the front side.

The sample consists of two aluminum sheets welded together. The left part of the welding is penetrating, while on the right side the welding does not penetrate resulting in a kissing bond. In the phase image at a frequency of $0.315 \mathrm{~Hz}$ (Figure 5 , top), the left and right part of the weld line appear different since the heat conduction in the penetrated welding is higher than in the kissing bond area. The lower image shows the phase angle measured along the welding and the related change

\section{Conclusion}

The performed measurements show that UBP allows for defect selective detection of damaged or low quality rivets. The measurement speed is higher than with ULT. The phase angle image obtained from the Fourier transformation of the temperature sequence has a much better signal to noise ratio than a single image taken from this temperature sequence. Additionally, due to the excitation method, the images are defect selective. Only areas with enhanced loss angle - correlated with damages - appear in the image. A limitation of this method is damping of the elastic waves within the sample thereby limiting the size of area that can be monitored. This problem could be solved by using either more excitation power (which could be dangerous for the sample) or several sonotrodes simultaneously.

OBP seems to be a promising method for quality assurance of welding containing kissing bonds since the slight changes in heat conductivity due to the thickness of the welding affect the phase angle.

\section{Acknowledgements}

The authors are grateful to Dipl.-Ing. H. Dörner and Dipl.-Ing. R. Kehrle from the Institute of Airplane Design (IFB) of Stuttgart University for allowing us to use their Do 31 sample.

\section{REFERENCES}

[1] [1] FOURIER, J., "Théorie du mouvement de la chaleur dans les corps solides $1^{\text {re }}$ Partie“. In: Mémoires de l'Académie des Sciences 4 (1824), pp. 185-555

[2] BUSSE, G., "Optoacoustic phase angle measurement for probing a metal". In: Appl.Phys.Lett. Vol. 35 (1979), pp. 759-760

[3] NORDAL, P.-E., KANSTAD, S.O., "Photothermal radiometry". In: Physica Scripta Vol. 20 (1979), pp. 659-662

[4] ROSENCWAIG, A., "Photoacoustic microscopy". American Lab. 11 (1979), pp.39-49

[5] LEHTO, A., JAARINEN, J., TIUSANEN, T., JOKINEN, M., LUUKKALA, M., "Amplitude and phase in thermal wave imaging". In: Electr. Lett. Vol. 17 (1981), pp. 364-365

[6] THOMAS, R.L., POUCH, J.J., WONG, Y.H., FAVRO, L.D., KUO, P.K., ROSENCWAIG, A., "Subsurface flaw detection in metals by photacoustic microscopy". In: J.Appl.Phys. Vol. 51 (1980), pp. 1152-1156

[7] [7] BEAUDOIN, J.L., MERIENNE, E., DANJOUX, R., EGEE, M, "Numerical system for infrared scanners and application to the subsurface control of materials by photothermal radiometry". In: Infrared Technology and Applications, SPIE Vol. 590 (1985), p. 287

[8] KUO, P.K., FENG, Z.J., AHMED, T., FAVRO, L.D., THOMAS, R.L., HARTIKAINEN, J., "Parallel thermal wave imaging using a vector lock-in video technique". In: 
Photoacoustic and Photothermal Phenomena, ed. P. Hess and J. Pelzl. Heidelberg: Springer-Verlag (1987), pp. 415-418

[9] HENNEKE, E. G., REIFSNIDER, K. L., STINCHCOMB, W. W., "Thermography - An NDI method for damage detection". In: Journal of Metals, 31 (1979), pp. 11-15

[10] MIGNOGNA, R.B., GREEN, R. E. Jr., HENNEKE, E.G., REIFSNIDER, K.L., "Thermographic investigations of high-power ultrasonic heating in materials". In: Ultrasonics 7 (1981), pp. 159-163

[11] RANTALA, J., WU, D., BUSSE, G., „Amplitude Modulated Lock-In Vibrothermography for NDE of Polymers and Composites". In: Research in Nondestructive Evaluation Vol. 7 (1996), pp. 215-218

[12] Patent DE 4203272

[13] ZWESCHPER, Th., WU, D., BUSSE, G., "Detection of loose rivets in aeroplane components using lockin thermography". In: QIRT 98, Lodz, Poland, Akademickie Centrum Graficzno-Marketingowe Lodart S.A., Lodz. ISBN 83-87202-88-6 (1999), pp. 161-166

[14] ZWESCHPER, Th., DILLENZ, A., BUSSE, G., "Ultrasound Lockin Thermography an NDT Method for the Inspection of Aerospace Structures". In: QIRT 2000, Lodart S.A.: Akademickie Centrum Graficzno - Marketingowe (2001) , pp. 224-229, ISBN 83-89003-45-7

[15] Maldague, X., Marinetti, S., "Pulse Phase Infrared Thermography". In: J. Appl.Phys. 79-5 (1996), pp. 2694-2698.

[16] Patent DE 10059854.4

[17] Galmiche, F., Maldague, X., Vallerand, S., Couturier, J.-P., "Pulsed Phased Thermography with the Wavelet Transform". In: QNDE, Montreal (1999), pp. 609615

[18] BUSSE, G., "Photothermal transmission probing of a metal". In: Infrared Physics 20 (1980), pp. 419-422

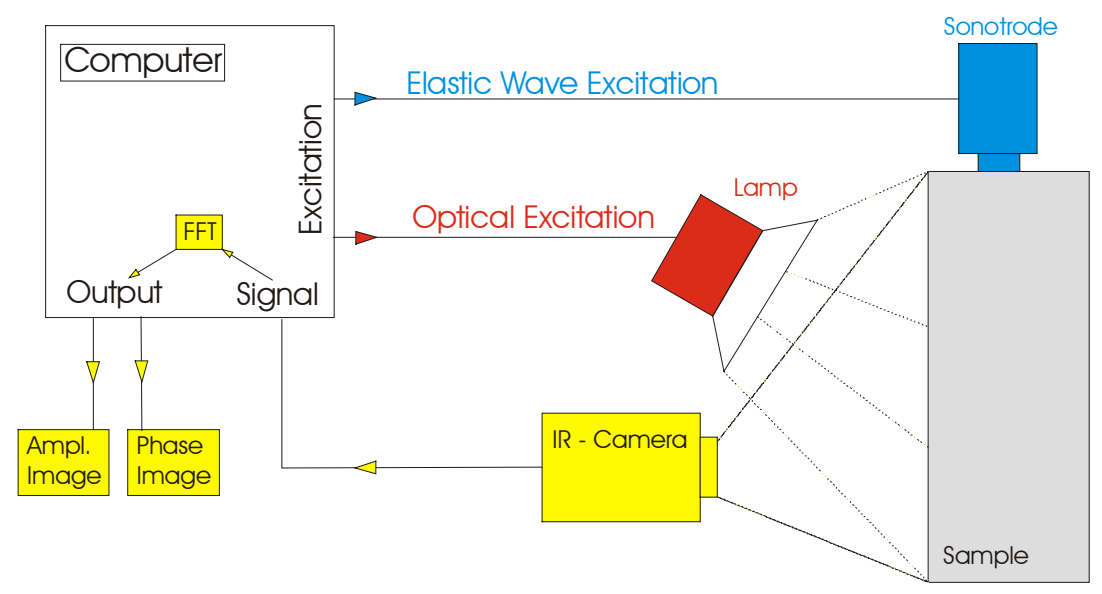

Fig. 1. Experimental Set-up of Lockin Thermography 

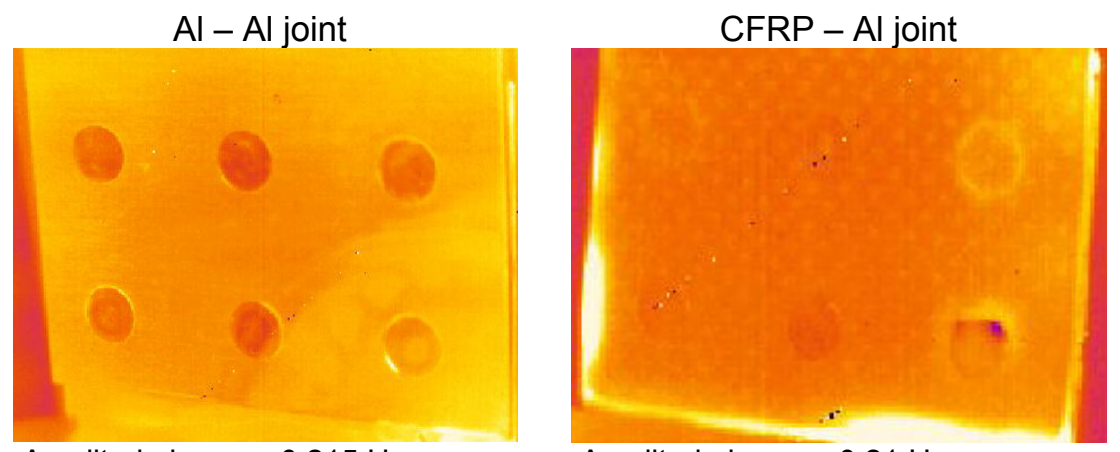

Amplitude image : $0.215 \mathrm{~Hz}$

Amplitude image : $0.21 \mathrm{~Hz}$

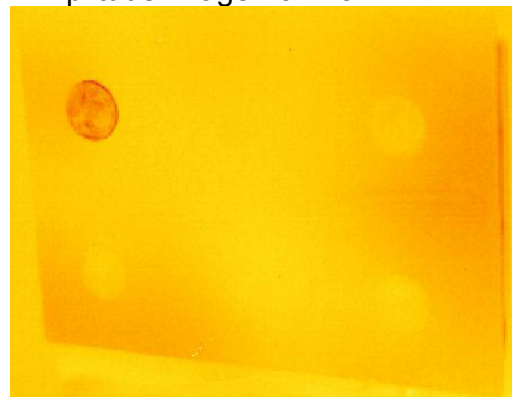

Phase image: $0.215 \mathrm{~Hz}$

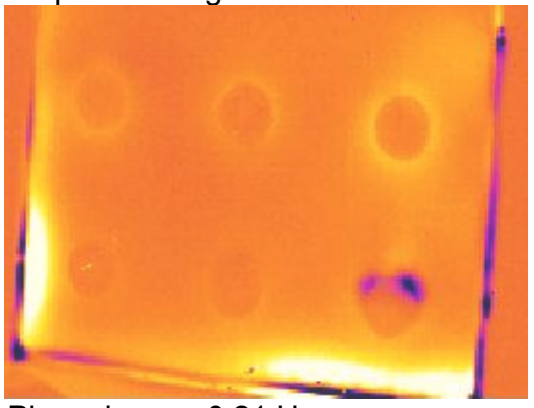

UBP, burst $200 \mathrm{~ms}, 1.6 \mathrm{~kW}$

Phase image: $0.21 \mathrm{~Hz}$

Fig. 2. Left: Rivets in Al-Al Joint; Right: Rivets in CFRP-Al Joint
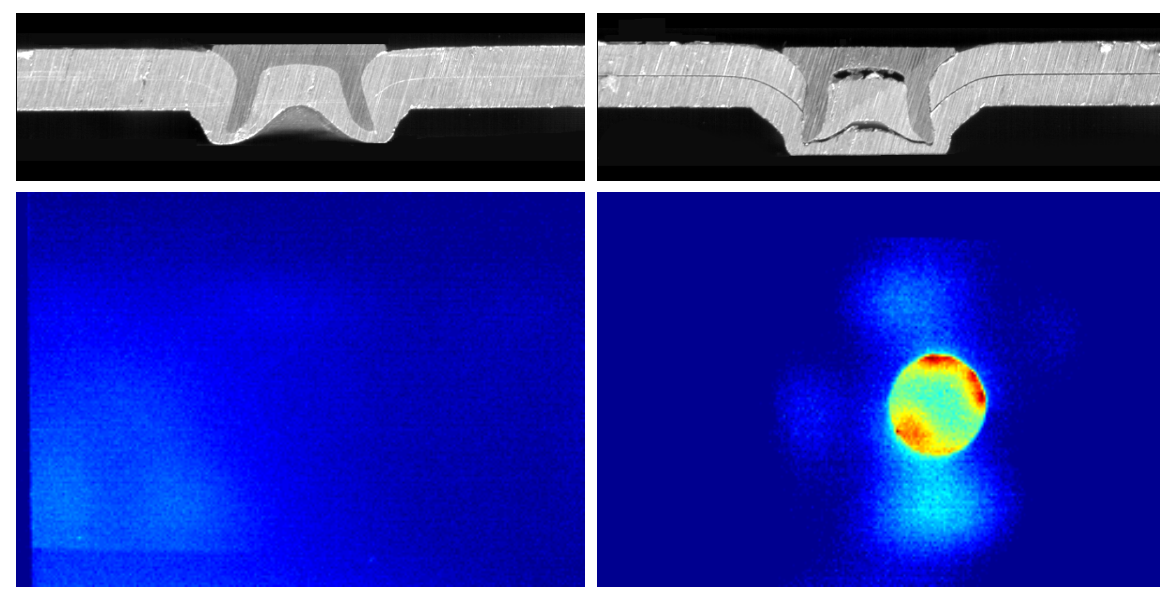

Fig.3. Punched Rivets, Cross Section and UBP Phase Image: $0.54 \mathrm{~Hz}$ 


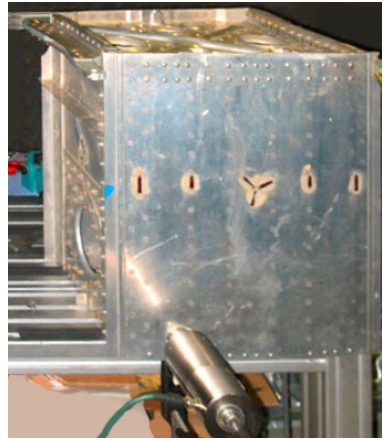

Photo of Do 31 wing-box with sonotrode for excitation

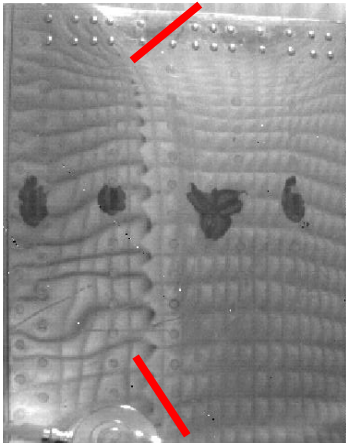

Amplitude image: $0.175 \mathrm{~Hz}$

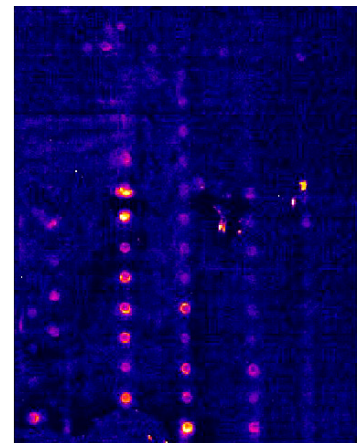

Phase image: $0.175 \mathrm{~Hz}$

Fig. 4. Wing-Box of Do 31 After Torsion Testing, UBP: Burst 500 ms, 2 kW
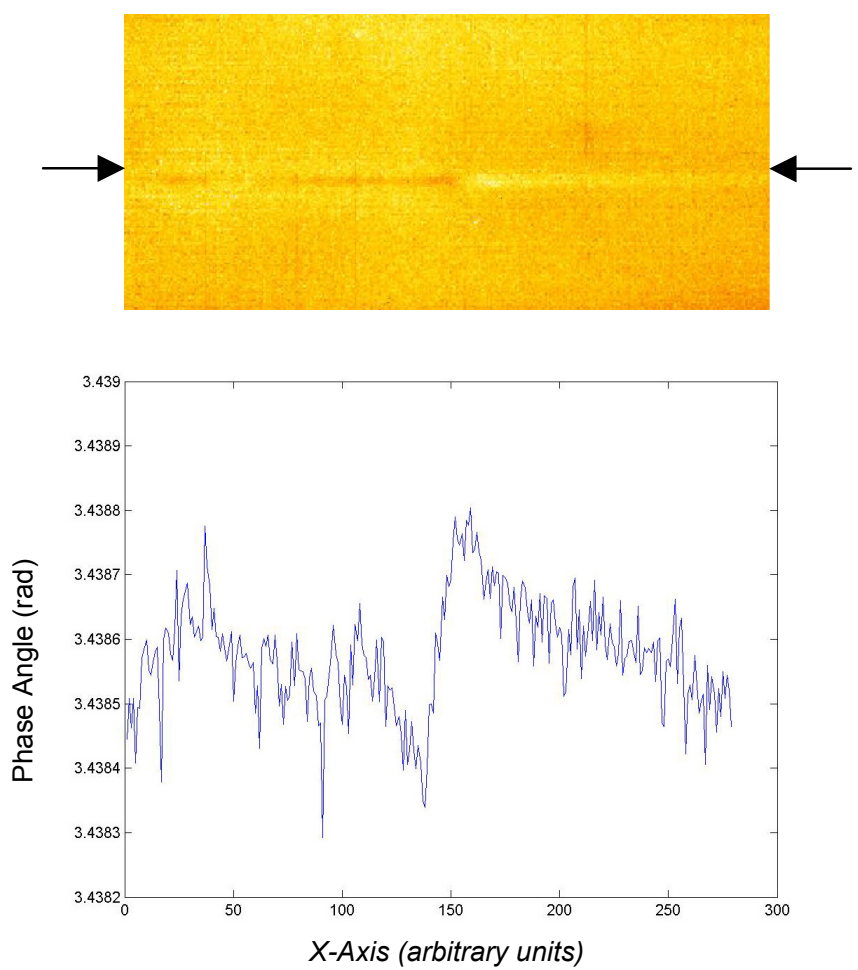

Fig. 5. Laser Beam Welding of Aluminum Sheets, Top: OBP Phase Image: $0.315 \mathrm{~Hz}$; Lower: Phase Angle along Welding. Arrows indicate weld line and $x$-axis for phase angle plot 